\title{
Reproductive Biology of Bothrops erythromelas from the Brazilian Caatinga
}

\author{
Verônica Alberto Barros, ${ }^{1,2,3}$ Claudio Augusto Rojas, ${ }^{2,4}$ and Selma Maria Almeida-Santos ${ }^{1,2}$ \\ ${ }^{1}$ Animal Biology Postgraduate Programme, São Paulo State University (UNESP), 2265 Cristovão Colombo Street, \\ 15054-000 São José do Rio Preto, SP, Brazil \\ ${ }^{2}$ Laboratory of Ecology and Evolution, Butantan Institute, 1500 Vital Brasil Avenue, 05503-000 São Paulo, SP, Brazil \\ ${ }^{3}$ Department of Protected Areas, Ministry of the Environment in Brazil (MMA), Marie Prendi Cruz Building, SEPN 505 North, \\ Room 401, 70.730-542 Brasília, DF, Brazil \\ ${ }^{4}$ Department of Experimental Neurology, Federal University of São Paulo (UNIFESP), 669 Pedro de Toledo Street, \\ Research Building II, 04039-032 São Paulo, SP, Brazil
}

Correspondence should be addressed to Verônica Alberto Barros; veronica.barros@mma.gov.br

Received 9 September 2014; Accepted 29 October 2014; Published 16 December 2014

Academic Editor: Ariovaldo A. Giaretta

Copyright (C) 2014 Verônica Alberto Barros et al. This is an open access article distributed under the Creative Commons Attribution License, which permits unrestricted use, distribution, and reproduction in any medium, provided the original work is properly cited.

\begin{abstract}
The reproductive biology of Bothrops erythromelas, a small pit viper from the Caatinga, a semiarid biome in Brazil, is described based on analysis of individuals deposited in zoological collections. Males are smaller and also attain sexual maturity at a smaller size than females. Female reproductive cycle is seasonal with an extended period of secondary vitellogenesis and births occurring in a restricted period from late spring to early summer. Sperm storage in females may probably occur in infundibular tubular glands and uterine muscular twisting (UMT), which is a polymorphic condition within B. erythromelas. Seasonal spermatogenesis in males is variable with some intraspecific variation regarding the male reproductive stage per season. Most males are reproductively active during spring/summer and reproductively quiescent during autumn/winter, although some individuals vary (e.g., show testicular spermatogenesis and active sexual segment of the kidneys (SSK) during winter). The SSK could be identified in every male. Most males showed highly hypertrophied SSK in spring/summer and moderately hypertrophied SSK in autumn/winter. The ampulla ductus deferentis was observed and histochemical reactions were conducted. We discuss the probable influence of the unique environmental conditions of the Caatinga region and phylogenetic inertia in the reproductive patterns of this snake species.
\end{abstract}

\section{Introduction}

The Caatinga domain, a mosaic of thorny bushes and seasonal dry forest, is a semiarid biome exclusive to Brazil. It is characterized by an extremely irregular rainfall pattern with severe dry seasons in some years [1]. Reptiles that live in arid environments may show physiological, behavioral, ecological, and morphological adaptations related to water scarcity in the environment [2]. Recently, a long-term study in the field showed that timing of parturition is influenced by rainfall seasonality in Crotalus atrox, a pit viper species from the Sonoran Desert [3]. To our knowledge, few studies addressed questions related to the influence of rainfall in the determination of reproductive strategies in snakes $[3,4]$. Pit viper species from the Caatinga region are good models to explore questions on the influence of environmental variables in the reproductive cycles because this region has unique characteristics regarding patterns of temperature and rainfall [1], and some data on reproduction of pit viper species from the Neotropical region including species from the Caatinga region are available for comparisons [4-9].

Bothrops erythromelas is a terrestrial and nocturnal species, responsible for many snakebites in Northeastern Brazil, occurring both in dry and wet habitats in the Caatinga vegetation [10-12]. This small pit viper $(55 \mathrm{~cm}$ snout-vent length (SVL) - female average size) [13] is a dietary generalist that feeds on frogs, lizards, mammals, and centipedes [11] and belongs to the Bothrops neuwiedi group [14]. Previous reports of B. erythromelas reproduction are anecdotal. Mating was observed in autumn (April and May) and births were 


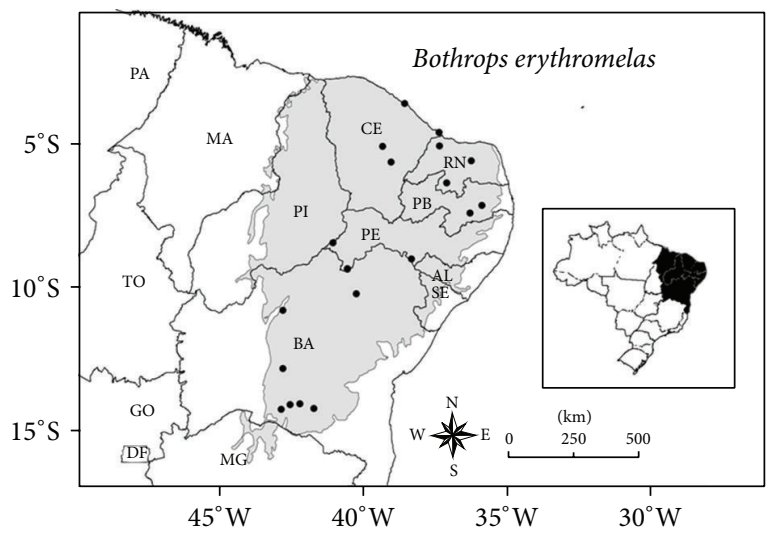

(a)

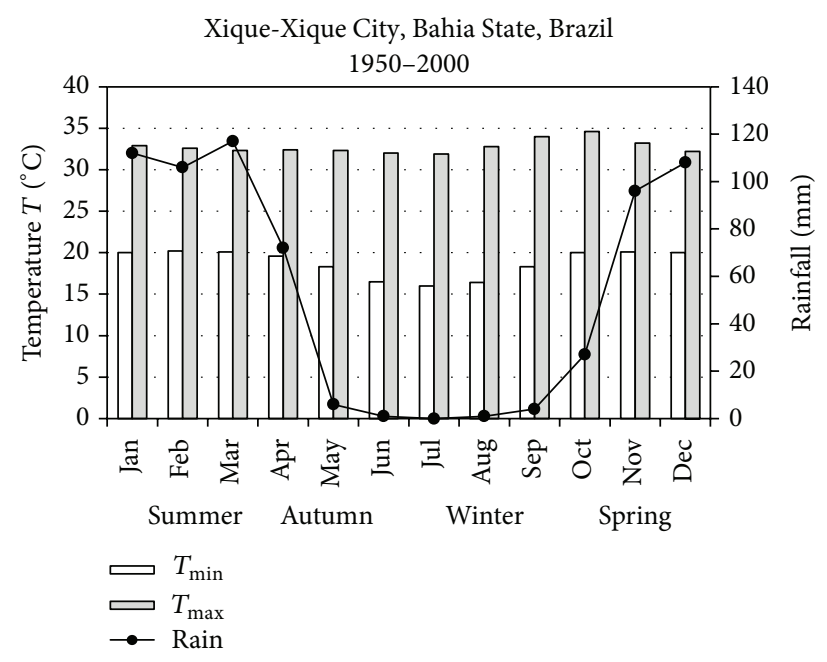

(b)

Figure 1: (a) Geographical origin of Bothrops erythromelas specimens sampled for this study in Northeastern Brazil. Caatinga is marked in gray. (b) Climatic pattern of the Caatinga.

observed in summer (January and February) in captivity $[5,15]$.

The aim of this study is to describe the reproductive biology of $B$. erythromelas, considering male and female reproductive cycles, sperm storage, sexual maturity, and dimorphism. We discuss the existence of a strong phylogenetic component in the determination of Bothrops reproductive patterns [5] versus the hypothesis of an environmentally cued reproductive pattern for $B$. erythromelas. If phylogenetic inertia plays a major role in determining reproductive cycles, we would expect to find the same reproductive timing for species that live under different environmental conditions (i.e., species from different biomes showing similar reproductive cycles). On the other hand, if patterns of temperature, rainfall, prey availability, or other environmental variables strongly affect reproductive cycles, we would expect to see a different reproductive pattern for B. erythromelas in comparison to Bothrops species from other biomes. Thus, we looked for differences and similarities in the reproductive characteristics between pit vipers from the Caatinga and other regions in Brazil with distinct climates and environmental conditions.

\section{Materials and Methods}

We examined a total of 246 preserved specimens of Bothrops erythromelas (116 mature females, 97 mature males, and 33 immatures) held in the collections of the Instituto Butantan (IB), Universidade Federal da Bahia (UFBA), and Museu Nacional (MNRJ). Individuals were originally collected from 1927 to 2009 in the following states in the northeastern region of Brazil: Bahia (BA), Pernambuco (PE), Paraíba (PB), Rio Grande do Norte (RN), and Ceará (CE). A map showing the municipalities where snakes have been collected was made using Arc Gis (version 9.3) (Figure 1(a)).

To characterize the climatic patterns of the Caatinga region, climatograms were constructed for every municipality using DIVA-GIS (version 7.1.7) and WorldClim Database (current climate: 1950-2000, version 1.3, 10 min resolution). High temperatures are maintained throughout the year. Rainfall is seasonal, characterizing two well-defined seasons: the dry and wet seasons (Figure 1(b)). The coldest months were July and/or August (temperature ranging from $13.3^{\circ} \mathrm{C}$ to $32^{\circ} \mathrm{C}$ ) and the warmest months occurred between October and February, depending on the area (temperature ranging from $16.6^{\circ} \mathrm{C}$ to $34.6^{\circ} \mathrm{C}$ ). Annual precipitation varies between 424 and $978 \mathrm{~mm}$ amongst the sampled areas. Reproductive events are described according to austral seasons to allow comparisons with snake species from various parts of the world.

We measured snout-vent length (SVL) to the nearest $1 \mathrm{~mm}$, and after dissection the following data were recorded: (1) diameter of the largest ovarian follicle or presence of embryos in females; (2) presence/absence of uterine muscular twisting (UMT), a sperm storage site in the posterior uterus [4-6]; (3) presence of corpora lutea in the ovaries; (4) testicular length; (5) width of the distal ductus deferens. These measurements were taken to the nearest $0.1 \mathrm{~mm}$.

Ductus deferens was considered convoluted or nonconvoluted according to the macroscopic aspect. The presence of spermatozoa in the testes or ductus deferens in the histological analysis was used as the main criterion to determine sexual maturity in males. The convoluted aspect of the ductus deferens was used as an additional criterion. Females were considered mature if they had follicles in secondary vitellogenesis, based on the presence of oviductal embryos or corpora lutea in the ovaries. Individuals that did not present these characteristics were considered immature.

The reproductive cycle of mature females was determined by comparing the length of the largest ovarian follicle or oviductal embryo at different times of the year. Records of mating and parturition in captivity were also incorporated to complete the cycle $[5,15]$. Female oviduct $(N=8)$ was histologically examined to look for the presence of sperm. 


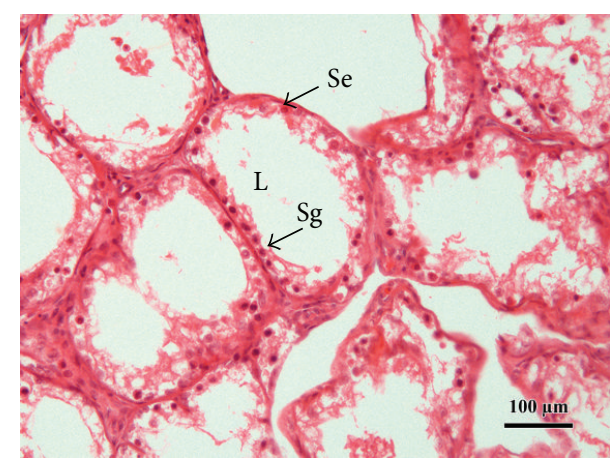

(a)

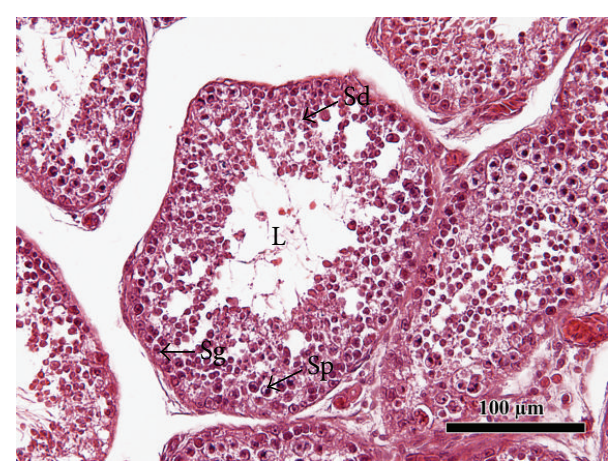

(b)

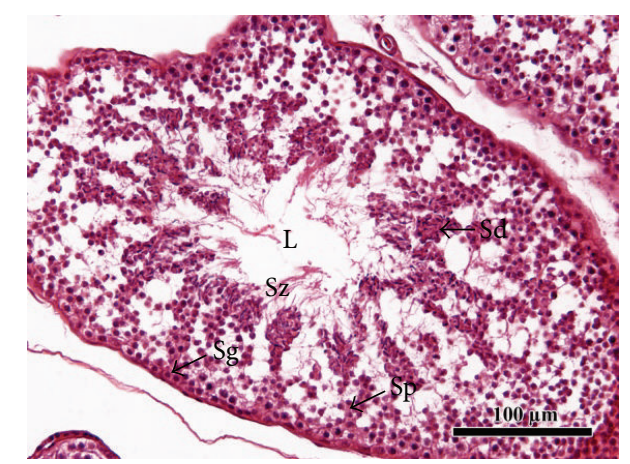

(c)

FIGURE 2: Spermatogenic stages in Bothrops erythromelas. (a) Regression. (b) Recrudescence. (c) Spermiogenesis. L = lumen; Sd = spermatid; $\mathrm{Se}=$ seminiferous epithelium; $\mathrm{Sg}=$ spermatogonia; $\mathrm{Sp}=$ primary spermatocyte; $\mathrm{Sz}=$ spermatozoa.

We also provide a brief description of oviducal regions. A preliminary analysis of the occurrence of UMT in Bothrops snakes was made using Mesquite (version 2.75) [16]. The phylogenetic hypothesis was adapted from Carrasco et al. [17] and data on presence of UMT was obtained for several species in published data [4-6] and V.A. Barros (umpubl. data) for $B$. atrox, B. diporus, and B. mattogrossensis. For B. erythromelas we attributed the status of polymorphic character for UMT because, although we have not observed any female showing UMT in this sample, there is one previous report of UMT for one female of B. erythromelas [5].

The reproductive cycle of mature males was analyzed considering macroscopic and microscopic changes of the testes and ductus deferens. The correlation between the testes length and the body length (SVL) was tested by linear regression. Analysis of covariance (ANCOVA) was employed to compare testes length between seasons, with SVL being the covariate. Differences in the diameter of the ductus deferens between seasons were analyzed using ANOVA. Testes $(N=$ $20)$, the distal portion of the ductus deferens $(N=20)$, and the kidneys $(N=10)$ of males were collected after dissection. We analyzed the spermatogenic cycle and the presence of sperm and changes in the epithelium of distal ductus deferens. Also, the secretory activity of the sexual segment of the kidneys (SSK) was investigated. The spermatogenic cycle was divided into three stages: (1) regression, presence of one or two layers of cells (spermatogonia and Sertoli cells) in the seminiferous tubules that may show some reminiscent spermatozoa from the previous spermatogenic season in the lumen, (2) recrudescence (mitotic and meiotic phase), characterized by the proliferation of cells from the seminiferous lineage, with presence of spermatogonia, spermatocytes, and initial spermatids, and (3) spermiogenesis, when the seminiferous tubules show rows of metamorphosing spermatids and abundant sperm in the lumen (Figure 2). Secretory granules were produced throughout the year in the SSK. Thus, we divided the SSK stages into "moderately hypertrophied" (medium density of granules) and "highly hypertrophied" (maximum density of granules) (Figure 3).

The organs were preserved in $70 \%$ alcohol and processed for light microscopy by the paraffin method. Sections taken at $5 \mu \mathrm{m}$ were stained with hematoxylin and eosin $(\mathrm{H} / \mathrm{E})$. In addition, sections of the ductus deferens were submitted to histochemical reactions: bromophenol blue (BB) for protein identification, periodic acid-Schiff (PAS) for identification of neutral carbohydrates, and alcian blue (AB) $\mathrm{pH} 2.5$ for carboxylated glycosaminoglycans. Slides were viewed under an Olympus BX51 microscope. Images of the slides were obtained via Image-Pro Express Olympus Program.

Sexual dimorphism in SVL was analyzed using the MannWhitney test. Statistical analyses were performed using Statistica software (version 7.0) and Bioestat (version 5.00). All variables were tested for normality and homoscedasticity prior to analysis. Only animals that were not maintained in captivity were included in the analysis. 


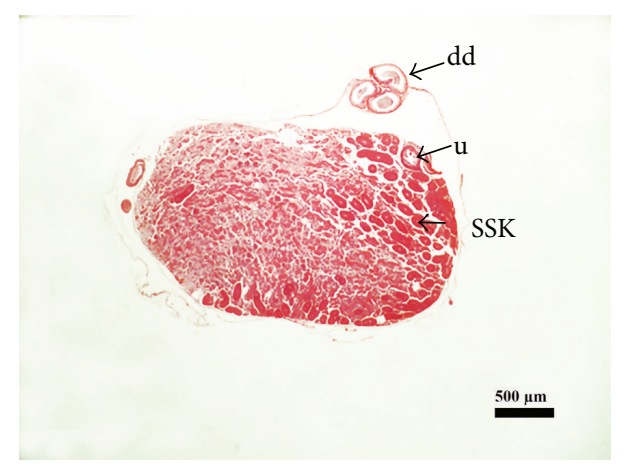

(a)

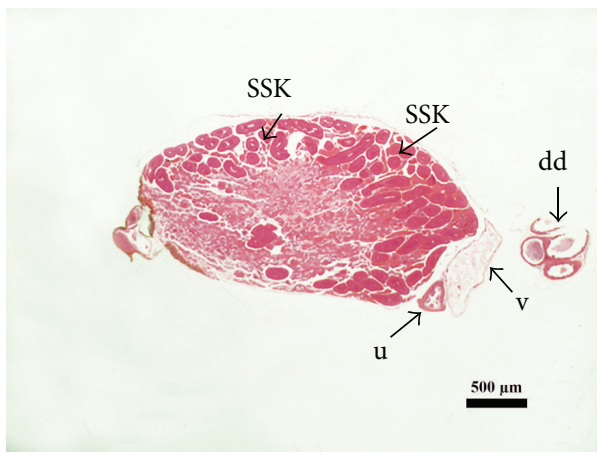

(c)

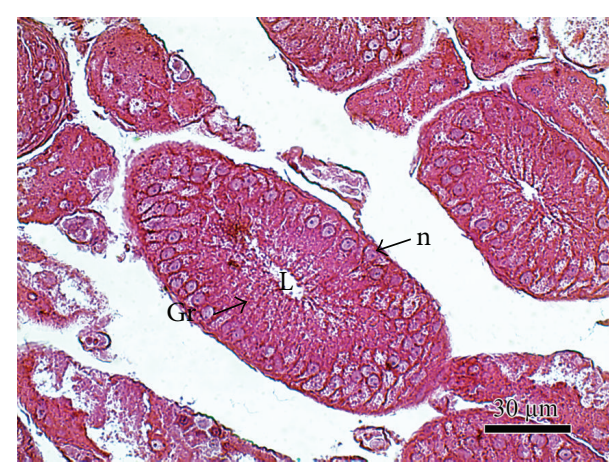

(b)

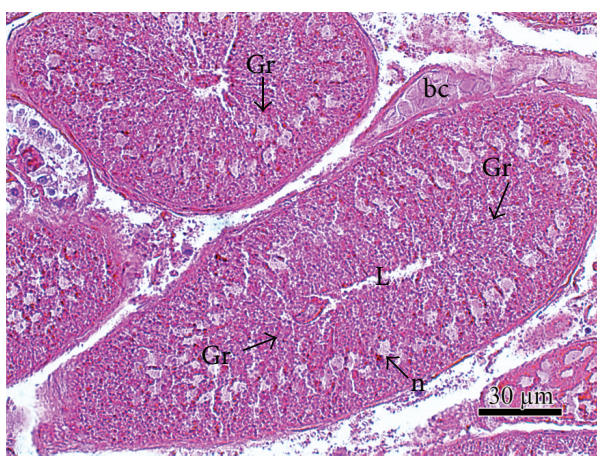

(d)

FIGURE 3: Sexual segment of the kidney (SSK) in Bothrops erythromelas. (a) General view of the kidney: moderately hypertrophied stage of the SSK. (b) Higher magnification of SSK in (a). (c) General view of the kidney: highly hypertrophied stage of the SSK. (d) Higher magnification of SSK in (c). dd: ductus deferens, u: ureter, L: lumen, n: nuclei, Gr: secretory granules, v: vein, bc: capillary blood.

\section{Results}

3.1. Sexual Maturation and Dimorphism. The smallest sexually mature female in our sample measured $37 \mathrm{~cm} \mathrm{SVL}$ and the smallest mature male measured $31.5 \mathrm{~cm}$ SVL. However, there were some larger individuals of both sexes that were still sexually immature. Mature males averaged $44.18 \mathrm{~cm} \mathrm{SVL}$ (range $=31.5-64.5 \mathrm{~cm}$ ) and mature females averaged $54.01 \mathrm{~cm}$ SVL (range $=37-92 \mathrm{~cm}$ ). Mature females were larger than conspecific males (Mann-Whitney, $Z=7.42, P<0.0001$ ).

3.2. Female. Primary vitellogenic follicles were present throughout the year and females with secondary vitellogenic follicles $(n=16)$ were collected during an extended period, from June to March. Embryos (average $=8$, range $=2$ to 13) were found in the oviducts in spring (October and November, $n=5$ ) (Figures 4 and 5). Neonates of a litter from Paraíba State averaged $15.78 \pm 0.4 \mathrm{~cm} \mathrm{SVL}(n=10)$.

Five different regions were identified in Bothrops erythromelas oviducts following an adaptation of the nomenclatures proposed by Aldridge [18] and Siegel et al. [19] (anterior and posterior infundibulum, anterior and posterior uterus, and vagina). The anterior infundibulum is characterized by a thin wall with irregular folding, tubular gland-like invaginations, and a simple cuboidal epithelium with many ciliated and some secretory cells (Figure 6(a)). The posterior infundibulum exhibits a slightly thicker lamina propria than the anterior infundibulum. The epithelium has some ciliated

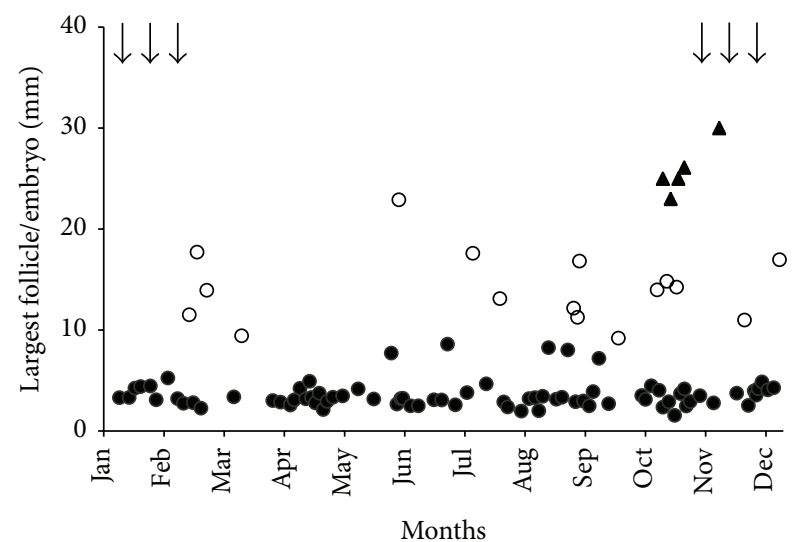

FIGURE 4: Female reproductive cycle: seasonal variation in diameter of the largest ovarian follicle and occurrence of embryos in mature females of Bothrops erythromelas. Solid circles = primary vitellogenic follicles; open circles = secondary vitellogenic follicles; triangles = embryos in the oviducts. Arrows indicate the parturition period reported in $[5,15,29]$.

and many secretory cells that exhibit a variable shape, from cuboidal to columnar in some regions (Figure 6(b)). Simple tubular glands with ciliated cells are most dense at the corners of the mucosal folds in the posterior infundibulum (Figure 6(c)). The incubation of embryos takes place in 


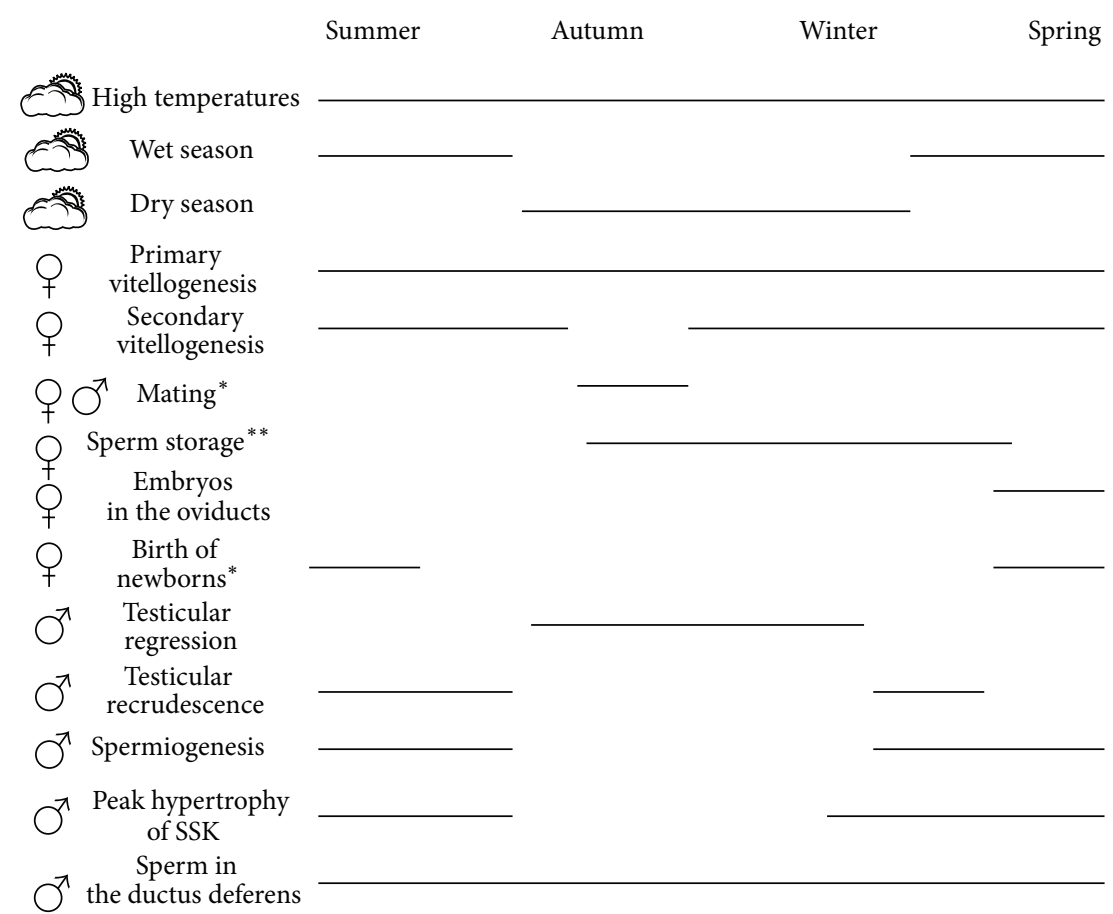

FIGURE 5: Timing of reproductive events in Bothrops erythromelas and climatic conditions in Brazilian Caatinga. * Observations in captivity, ** Inferred by the dissociated timing between mating and ovulation.

the anterior uterus which is less folded and presents less deep furrows in comparison to the infundibulum (Figure 6(d)). The lamina propria is constituted of uterine glands and the epithelium is simple cuboidal ciliated with some secretory cells in the anterior uterus (Figure 6(d)). The posterior uterus exhibits a pseudostratified epithelium with ciliated and secretory cells and it is characterized by the presence of deep furrows, the absence of uterine glands and external circular and longitudinal muscular layers (Figure 6(e)). The vagina is constituted by a tall columnar epithelium with many secretory and some ciliated cells (Figure 6(f)). Females were sampled through different seasons-late summer $(n=1)$, autumn $(n=5)$, winter $(n=1)$, and spring $(n=1)-$ and the oviduct of every individual sampled showed the structures described above. However, sperm was not found in any portion of these oviducts. The posterior uteri of all B. erythromelas females examined were straight and did not show any twisting (Figure $6(\mathrm{~g})$ ). Uterine muscular twisting (Figure 6(h)), a sperm storage site in the posterior uterus described for neotropical pit vipers [4-6], was not observed in any female sampled. A reconstruction of character state based on the presence of UMT in 15 species of bothropoid pit vipers shows that the ancestral of the Bothrops lineage exhibited an UMT (Figure 6(i)).

3.3. Male. Testes length was positively correlated with SVL $\left(F=45.88, r^{2}=0.33, P<0.0001\right)$ and no significant differences were observed among seasons $(F=0.57, P=0.64)$. Histological analysis showed that seasonal spermatogenesis in B. erythromelas males was variable. Most males are reproductively active during spring/summer and are reproductively quiescent during autumn/winter. In the beginning of summer (December), males showed testes in regression with the presence of some reminiscent spermatozoa from the previous spermatogenic season in the lumen. From January to March (summer), both recrudescence and spermiogenesis with abundant sperm in the lumen of seminiferous tubules were observed. In autumn (April and June), the seminiferous epithelium of the testes was totally regressed, showing a single layer of spermatogonia and Sertoli cells resting upon the basal lamina. Testes in total regression were also observed in winter from the beginning to the middle of July. In the middle of July and August, the stages of recrudescence and spermiogenesis (with a huge amount of spermatozoa in the lumen) were also observed in some individuals. In spring, males showed testes in spermiogenesis with a lot of spermatids and spermatozoa in the lumen (Figures 2 and 5).

The SSK was observed in the kidneys of every male sampled but its condition varied from moderately to highly hypertrophied. Most males showed highly hypertrophied SSK in spring/summer and moderately hypertrophied SSK in autumn/winter. In summer, both conditions were observed, with most males showing a peak of SSK hypertrophy. In autumn, SSK was moderately hypertrophied in every male sampled. During winter, the SSK was moderately hypertrophied in most individuals and highly hypertrophied in a few males. In spring, the SSK of all males sampled was highly hypertrophied (Figures 3 and 5). We observed an association of males with active SSK (highly hypertrophied) and testes (mainly during spermiogenesis)

Sperm were present throughout the year in the ductus deferens. Ductus deferens width did not show any significant variation between seasons (ANOVA, $F=0.57, P=0.64$ ). The ductus deferens of $B$. erythromelas presented low and 


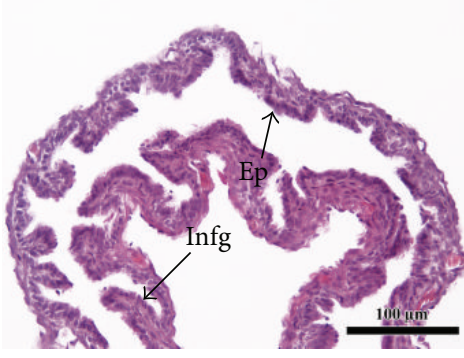

(a)

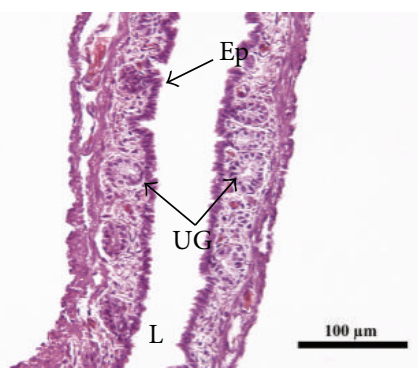

(d)

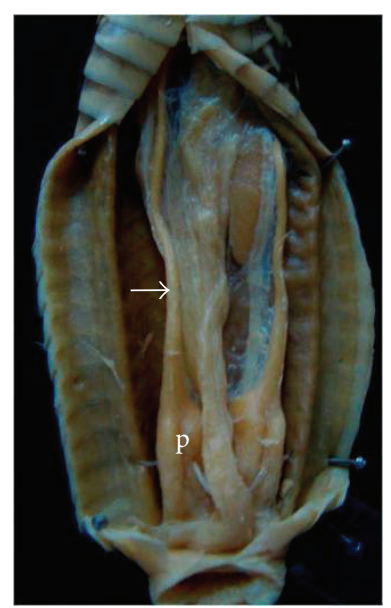

(g)

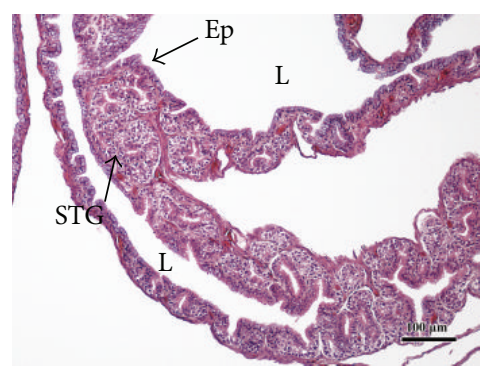

(b)

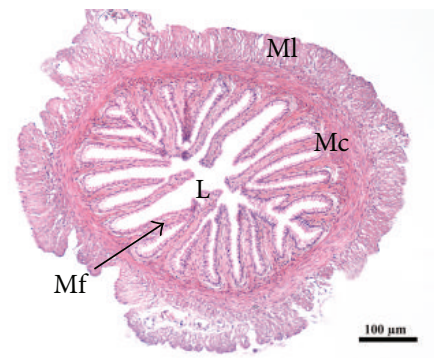

(e)

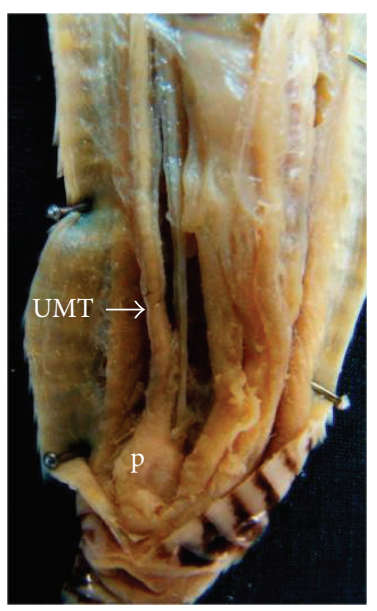

(h)

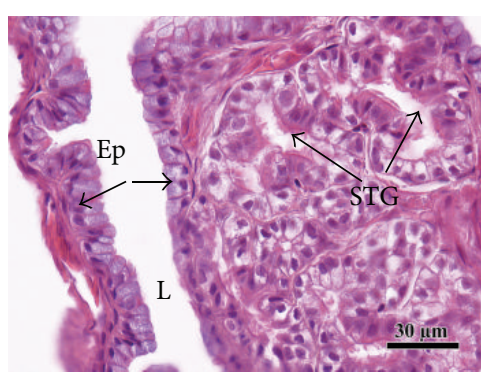

(c)

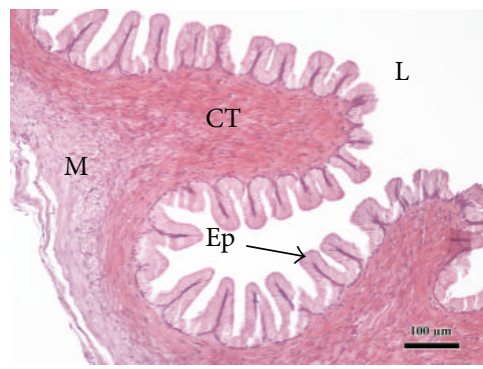

(f)

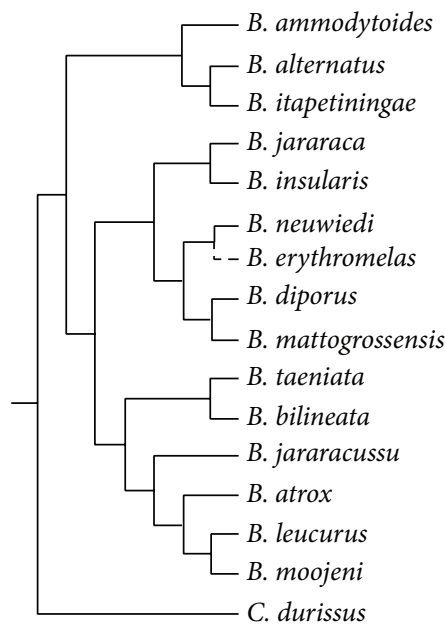

(i)

FIGURE 6: Histology of the female reproductive tract of Bothrops erythromelas. (a) Anterior infundibulum. (b) Posterior infundibulum. (c) High magnification of (b) showing simple tubular glands. (d) Anterior uterus. (e) Posterior uterus. (f) Vagina. (g) Macroscopic view of the posterior uterus in B. erythromelas showing a flat condition (arrow) in the absence of uterine muscular twisting (UMT). (h) Macroscopic view of the UMT in a related species, B. mattogrossensis. (i) Reconstruction of the presence of UMT (black) in the genus Bothrops using a phylogenetic hypothesis adapted from Carrasco et al. [17]. The polymorphic condition of UMT in B. erythromelas is represented by a dashed line. CT = connective tissue; Ep = epithelium; Infg = infundibular glands (tubular gland-like invaginations); $\mathrm{L}=$ lumen; $\mathrm{M}=$ muscularis; Mc $=$ muscularis (circular layer); $\mathrm{Ml}=$ muscularis (longitudinal layer); $\mathrm{Mf}=$ mucosal folds; $\mathrm{P}=$ pouch; $\mathrm{STG}=$ simple tubular gland; $\mathrm{UG}=$ uterine gland; UMT = uterine muscular twisting.

pseudostratified epithelium resting upon the basement membrane, which is surrounded by a thin circular muscular layer and an external serosa (Figure 7). The ampulla ductus deferentis (a region in the distal ductus deferens) exhibiting a higher epithelium with irregular projections and formation of crypts was observed in all seasons of the year but not in every male sampled (Figure 7). Results of histochemical reactions did not show any differences between the ampulla ductus deferentis and other portions of the distal ductus deferens. Positive reactions to BB (Figures 7(c) and 7(d)) and
PAS were observed in the apical portion of the epithelial cells in the ductus deferens including the ampulla. However, $\mathrm{BB}$ and PAS reactions were less intense than those for the basement membrane of the distal ductus deferens including the ampullary region. Negative reactions to PAS and BB were observed in the cytoplasm of these epithelial cells and sperm mass and all samples of the ductus deferens presented negative reactions to $A B$. Some secretory material that was not in contact with sperm mass exhibited PAS positive reaction in the ductus deferens. 


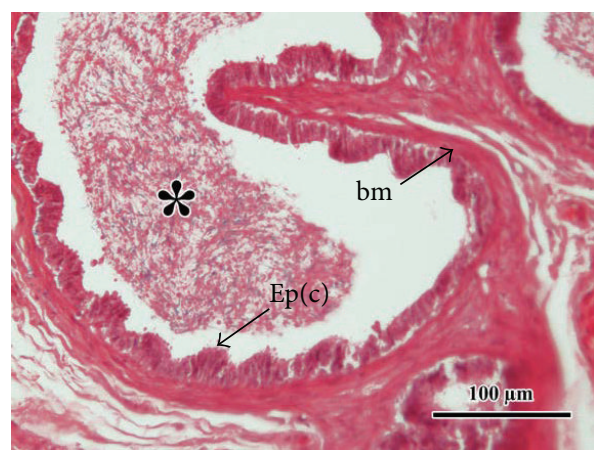

(a)

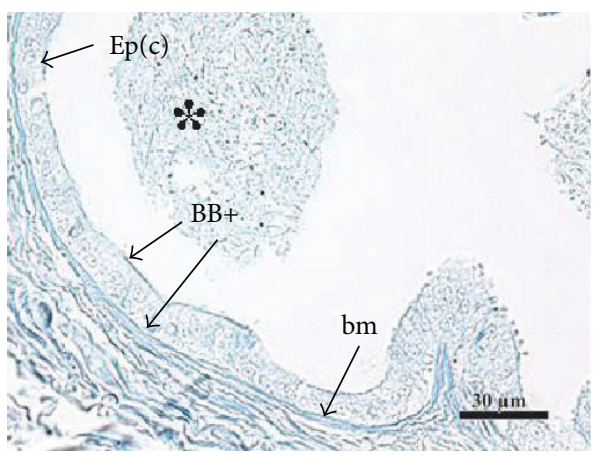

(c)

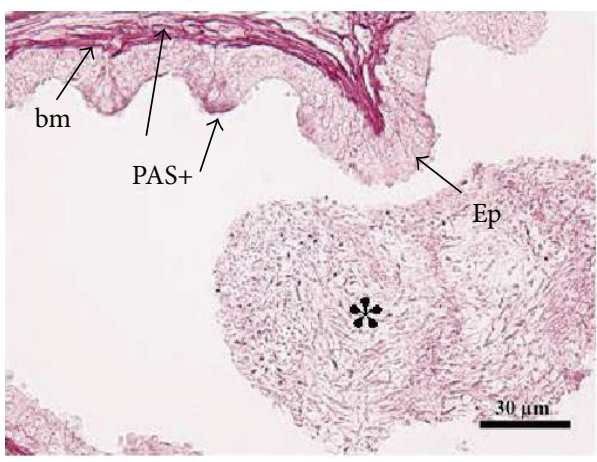

(e)

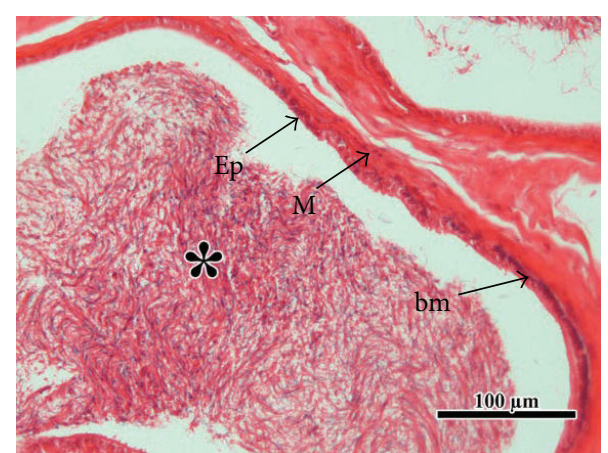

(b)

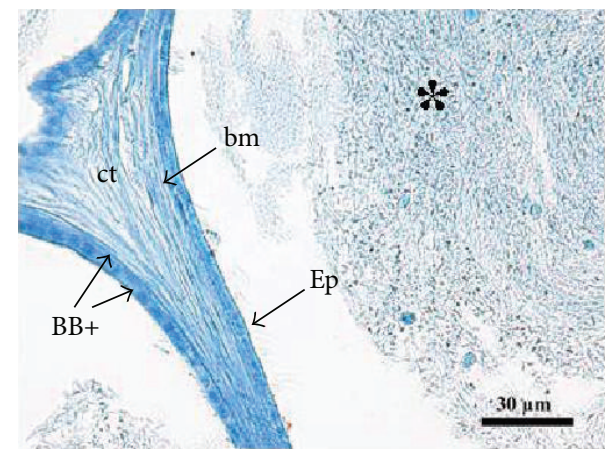

(d)

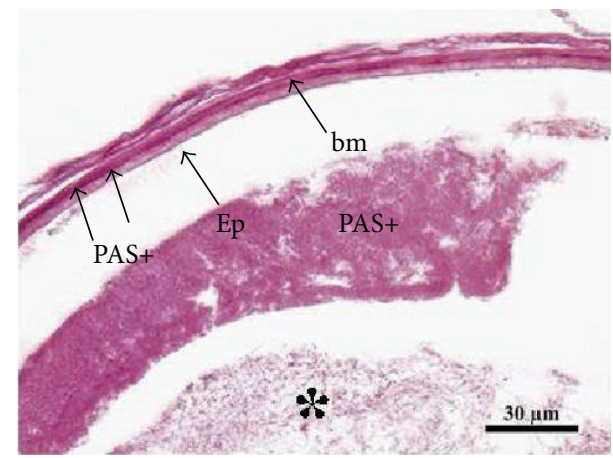

(f)

FIGURE 7: Light micrographs of the ductus deferens and ampulla ductus deferentis in Bothrops erythromelas. (a) Ampulla ductus deferentis showing the presence of folds and crypts in the epithelium. (b) Distal ductus deferens presenting low and pseudostratified epithelium. (c) Ampulla ductus deferentis stained with bromophenol blue. (d) Distal ductus deferens stained with bromophenol blue. (e) Reaction to PAS in the ampulla ductus deferentis. (f) Reaction to PAS in the distal ductus deferens. Asterisks indicate the sperm mass; bm $=$ basement membrane; $\mathrm{ct}=$ connective tissue; $\mathrm{Ep}=$ epithelium; $\mathrm{Ep}(\mathrm{c})=$ pseudostratified epithelium with formation of crypts; $\mathrm{M}=$ muscularis; $\mathrm{BB}+=$ positive reaction to bromophenol blue; PAS + = positive reaction to periodic-acid-Schiff.

\section{Discussion}

Although extended vitellogenesis may be considered as an indicator of continuous reproduction for some species, it does not seem to be a very reliable indicator of female reproductive seasonality for snakes $[4,20]$. The rates of yolk deposition in the follicles may vary among individuals according to many factors such as hormonal levels [21] or body condition [22]. The occurrence of embryos in the oviducts and births in captivity during a restricted period of the year are better evidences of a seasonal reproductive pattern [20]. Bothrops erythromelas showed a seasonal reproductive pattern, just like other Bothrops species [4, 5, 7-9].
Mating (autumn) and ovulation (spring) do not occur synchronously in B. erythromelas; thus females probably have some sperm storage strategy to guarantee fertilization and successful reproduction. Here, we described the presence of simple tubular glands in the posterior infundibulum of a Bothrops species for the first time. Although sperm was not found in these glands, they may be sperm storage tubules (SSTs) [19, 23-25], responsible for sperm storage after mating in $B$. erythromelas. Sperm may also be maintained in more caudal regions of the oviduct (vagina and posterior uterus) for variable periods of time [26] prior to migration to infundibular SSTs [6]. A contraction named "uterine muscular twisting" (UMT) has been macroscopically observed in 
the posterior uterus of the neotropical rattlesnake (Crotalus durissus) and several species from the main lineages of the genus Bothrops [4-6]. Sperm is maintained by UMT since mating occurs in autumn until the oviduct relaxes near the timing of ovulation in spring and sperm moves to cranial portions of the oviduct [5]. Almeida-Santos and Salomão [5] observed an UMT in a single female of B. erythromelas showing ovarian follicles in primary vitellogenesis during January. Although we have analyzed a large sample size of females for this study, we failed to find a B. erythromelas specimen showing UMT. Thus, we conclude that UMT may be a polymorphic character within B. erythromelas, which means that sperm storage strategies may be diversified in females of this species. Some B. erythromelas females may synchronize the reproductive cycle storing sperm by means of an UMT [5], while most females of this species may show sperm storage in other oviductal regions, including infundibular tubular glands which are specialized sperm storage receptacles present in most species of snakes [19]. Thus, UMT is not an obligatory component of the reproductive cycle for B. erythromelas, different from most Bothrops species studied to date [5], including the ancestor of Bothrops which probably showed UMT as an obligatory component of the reproductive cycle considering the preliminary reconstruction of UMT presence in bothropoid pit vipers presented herein. Vitellogenesis occurred almost throughout the year in B. erythromelas, and as it triggers the cranial migration of spermatozoa to infundibular sperm receptacles [27], sperm may ascend the oviduct right after copulation and remain stored in SSTs.

Histological analysis of the oviduct of a larger sample of B. erythromelas females and other species of neotropical pit vipers is also needed for a better understanding of female sperm storage strategies in this group of snakes. Sperm storage strategies may be very complex and present a wide array of variations. Recently, Booth and Schuett [28] reported that an eastern diamond-backed female rattlesnake (Crotalus adamanteus) copulated when it was sexually immature. After being in captivity, isolated from males for 5 years, this female produced a normal clutch of 19 offspring. Genetic analysis confirmed the occurrence of long-term sperm storage of exceptional duration for the first time [28].

Although direct evidence of timing of mating (e.g., observations in the wild or presence of sperm in the vagina or posterior uterus) is not available for B. erythromelas, there are some reports of mating in captivity during autumn (April and May) $[5,29]$. The SSK hypertrophy is under the control of testosterone and it is linked to the mating season in several snake species [30, 31]. In B. erythromelas, some intraspecific variation occurs in timing of SSK hypertrophy with most males having a peak of SSK hypertrophy in spring/summer, although this peak may also occur in winter for some individuals. Variations in climatic conditions among different years could be an explanation for these differences but further research is needed to test this hypothesis. Alternatively, the production of sexual granules in the SSK throughout the year may be indicative that timing of mating may be more plastic in B. erythromelas than in other Bothrops that show a mating period restricted to autumn.
Pregnancy in the warmest season of the year (e.g., summer) is the best period for embryonic development in viviparous squamates [32]. This is one hypothesis to explain the evolution of the dissociation between mating in autumn, sperm storage during autumn/winter, ovulation in spring, and pregnancy and birth of newborns in summer, for pit viper species that live in colder climates $[5,33]$. However, temperature may not be a limiting factor for embryonic development in B. erythromelas because high temperatures are maintained throughout the year in the Caatinga. Thus, optimal embryonic development would be possible at any time of the year. However, the available dataset shows just the opposite (i.e., embryos in the oviducts and births occur in a restricted period of the year). The birth of newborns in the wet season is a characteristic of $B$. erythromelas shared with every species of the genus Bothrops studied to date [5]. One hypothesis is that parturition timing in bothropoid species (from the end of spring through summer) may have been influenced by rainfall seasonality because environmental conditions are more favorable to the survival of newborns in the wet season (e.g., higher prey availability) [5]. However, the timing of reproductive events (mating, sperm storage, ovulation, pregnancy, and parturition) is very similar within females of the genus Bothrops, regardless of the different actual environmental conditions where different species occur at the present time (i.e., bothropoid females from different species living in different biomes like the Atlantic Forest, Pampas, Cerrado, and Caatinga show similar reproductive patterns) $[4,5,7-9]$. This similarity in reproductive timing in Bothrops species may be attributed to the influence of phylogenetic inertia in the determination of reproductive events for females.

Low fecundity is a characteristic of the B. neuwiedii group which may be related to the small body size of this snake lineage (with the exception of $B$. mattogrossensis from the Brazilian "Pantanal" that may have 37 newborns per clutch) $[7,8,34]$. Clutch size and SVL of newborns in a clutch of B. erythromelas from Paraiba State described herein were very similar to a report of a clutch from Bahia State [15]. On the other hand, Silva [29] reported the birth of a clutch of 8 newborns of B. erythromelas which were larger than the newborns analyzed for this study. Thus, body mass and length (SVL) of newborns seem to be plastical characters in B. erythromelas showing some variation related to clutch size: newborns may be larger and heavier when clutch size is smaller. Further studies should test the factors that may influence clutch size and the size of newborns, including an assessment of environmental influence in the variation of clutch size, size, and fitness of the newborns in neotropical pit vipers; see [35, 36].

Studies on surveillance and viability of stored sperm in the ductus deferens are also important for B. erythromelas in order to understand if males would really be ready to mate successfully (i.e., produce an offspring) in any season of the year considering that sperm was present throughout the year in the ductus deferens. The ampulla ductus deferentis, which may be related to the sperm surveillance and storage in squamate species $[31,37,38]$, was also observed in the ductus deferens of $B$. erythromelas throughout the year but 
not in every male sampled. Histochemical results of the ductus deferens including the ampulla ductus deferentis were similar to those described for the sleep snake, Sibynomorphus mikanii: positive reactions to histochemical testes indicated the presence of proteins and neutral carbohydrates in the apical portion of epithelial cells in both species. However, in $S$. mikanii positive reactions were identified in the secretory material associated with sperm mass [31], but not in B. erythromelas. The PAS+ secretory material was not in contact with sperm mass perhaps due to an artifact of the technique.

Timing of seasonal spermatogenesis in males was variable with periods of complete regression; thus the male reproductive cycle may be classified as seasonal semisynchronous at the populational level and discontinuous cyclical at the individual level [20]. Sperm production was observed mainly during spring/summer, and regression of the seminiferous epithelium was observed mainly in autumn/winter but some individuals varied (e.g., showed spermatogenesis during winter), perhaps due to variations in climatic conditions in different years. Temperatures are high throughout the year in the Caatinga domain, which, in theory, allows sperm production to occur at any season [39]. This hypothesis was confirmed for B. erythromelas, as spermatogenesis occurred in winter in some individuals, different from populations of pit vipers from colder regions in Brazil and also different from a population of a sympatric pit viper from the Caatinga, the rattlesnake $C$. durissus [6]. Therefore, male reproductive patterns of $B$. erythromelas seem to be very complex and someway influenced by environmental conditions. Studies in the field are necessary to test if there is an association between rainfall seasonality and occurrence of reproductive events such as sperm production and mating [3]. Considering that sperm production may have relatively high reproductive costs [40], it may be adaptative to start spermatogenesis at different periods for a species that lives in a semiarid biome like the Caatinga. Severe dry seasons may alter prey availability and the scarcity of food may affect body condition making costs of spermatogenesis too high in some periods. Populations of important B. erythromelas prey (e.g., anurans and centipedes that correspond to more than $50 \%$ of their diet) are influenced by rainfall seasonality and may be more abundant in the wet (rainy) season $[41,42]$. Thus, rainfall may have a role in determining the timing of spermatogenesis in B. erythromelas as these periods are coincident. Males may show an increase in feeding activity to support the energetic demand of sperm production as some items of their diet are not highly energetic (anurans, centipedes, lizards) if compared to mammals. An assessment of feeding seasonality in B. erythromelas may contribute to test this idea.

Fluctuations of prey populations may possibly influence reproductive strategies of both young (e.g., process of sexual maturation) and adult or sexually mature individuals (e.g., reproductive cycles) of $B$. erythromelas because both rely on the same kinds of prey (i.e., no ontogenetic changes in the diet) [11]. Studies on different populations of the neotropical rattlesnake Crotalus durissus showed that individuals of populations that live under different climatic conditions may reach sexual maturity at different sizes [6]. Here, because our dataset was not appropriate to address questions considering different populations, we preferred to establish a comprehensive pattern of reproduction for the species.

Sexual maturation and dimorphism of B. erythromelas are conservative within Bothrops lineage. Males of Bothrops erythromelas attained sexual maturity at a smaller size than females like several Bothrops species [4, 7-9] and snakes in general [43]. Female snakes may have late sexual maturation in relation to conspecific males because female reproductive costs, with the production of an offspring, are higher and larger females usually produce larger clutches [44], but see also [45]. Considering the sexual dimorphism of mature individuals, a phylogenetically conserved pattern was also observed: B. erythromelas females were larger than males as in other species of this genus [7-9]. This is the most common sexual dimorphism pattern in snakes and it is usually related to the absence of male-male fighting behavior [44, 46]. Although $B$. paulensis males showed agonistic behavior in captivity in the presence of the female before courtship started [29], there is no report of male-male fighting for any species of the $B$. neuwiedi group, including $B$. erythromelas. In this genus, male-male fighting has already been reported for the Bothrops atrox group [5].

Bothrops erythromelas is a good model for future studies on the influence of environmental variables in reproductive timing and intraspecific variability in reproductive condition. Here, we propose some possible influence of temperature, rainfall, and prey availability in B. erythromelas reproductive pattern. Alternatively, the interaction among a group of environmental variables not considered herein [47] may influence the timing of reproductive events in B. erythromelas. Future studies using larger samples of B. erythromelas for histological analysis, tests of hypothesis in the wild, and the study of other species of Neotropical pit vipers will shed light on the questions that we have pointed out herein.

\section{Conclusions}

Male and female reproductive cycles of $B$. erythromelas are seasonal, just like other Bothrops species. Timing of reproductive events in females is similar to other bothropoids that live in different biomes (under different environmental conditions), which shows the influence of phylogenetic inertia in the determination of reproductive events. However, some reproductive strategies in $B$. erythromelas females seem to be more plastical than in other neotropical pit vipers (e.g., UMT is a polymorphic condition for this species). For males, timing of spermatogenesis and peak of SSK hypertrophy were linked to the wet season for most individuals. The presence of variability in timing of spermatogenesis and SSK hypertrophy also indicates that actual environmental conditions may influence the timing of reproductive events. However, studying the male reproductive cycle of other Bothrops species is still necessary to establish comparisons.

\section{Conflict of Interests}

The authors declare that there is no conflict of interests regarding the publication of this paper. 


\section{Acknowledgments}

The authors thank F. L. Franco, P. Passos, and R. M. Lira-daSilva for allowing access to the collections; V. J. Germano, P. Pinna, and D. P. Coelho for the technical assistance; C. Jared and M. Antoniazzi for allowing the use of equipments; the anonymous referees for their comments which improved the paper. FAPESP provided fellowships to V.A. Barros (2008/56169-5 and 2012/15037-4).

\section{References}

[1] A. N. Ab'Saber, Os domínios de natureza no Brasil: potencialidades paisagísticas, Atêlie Editorial, São Paulo, Brazil, 2003.

[2] F. H. Pough, R. M. Andrews, J. E. Cadle, M. L. Crump, A. H. Savitzky, and K. D. Wells, Herpetology, Pearson Prentice Hall, Upper Saddle River, NJ, USA, 2004.

[3] G. W. Schuett, R. A. Repp, S. K. Hoss, and H. W. Herrmann, "Environmentally cued parturition in a desert rattlesnake, Crotalus atrox," Biological Journal of the Linnean Society, vol. 110, no. 4, pp. 866-877, 2013.

[4] V. A. Barros, C. A. Rojas, and S. M. Almeida-Santos, "Is rainfall seasonality important for reproductve strategies in viviparous neotropical pit vipers? A case study with Bothrops leucurus from the Brazilian Atlantc Forest," Herpetological Journal, vol. 24, no. 2, pp. 69-77, 2014.

[5] S. M. Almeida-Santos and M. G. Salomão, "Reproduction in neotropical pitvipers, with emphasis on species of the genus Bothrops," in Biology of the Vipers, G. W. Schuett, M. Höggren, M. E. Douglas, and H. W. Greene, Eds., Eagle Mountain Publishing, Eagle Mountain, Calif, USA, 2002.

[6] V. A. Barros, L. R. Sueiro, and S. M. Almeida-Santos, "Reproductive biology of the neotropical rattlesnake Crotalus durissus from northeastern Brazil: a test of phylogenetic conservatism of reproductive patterns," Herpetological Journal, vol. 22, no. 2, pp. 97-104, 2012.

[7] M. T. Hartmann, O. A. V. Marques, and S. M. AlmeidaSantos, "Reproductive biology of the southern Brazilian pitviper Bothrops neuwiedi pubescens (Serpentes, Viperidae)," Amphibia Reptilia, vol. 25, no. 1, pp. 77-85, 2004.

[8] C. Monteiro, C. E. Montgomery, F. Spina, R. J. Sawaya, and M. Martins, "Feeding, reproduction, and morphology of Bothrops mattogrossensis (Serpentes, Viperidae, Crotalinae) in the Brazilian Pantanal," Journal of Herpetology, vol. 40, no. 3, pp. 408-413, 2006.

[9] C. Nogueira, R. J. Sawaya, and M. Martins, "Ecology of the pitviper, Bothrops moojeni, in the Brazilian cerrado," Journal of Herpetology, vol. 37, no. 4, pp. 653-659, 2003.

[10] R. M. Lira-da-Silva, Y. F. Mise, L. L. Casais-e-Silva, J. Ulloa, B. Hamdan, and T. K. Brazil, "Serpentes de importância médica do nordeste do Brasil," Gazeta Médica da Bahia, vol. 79, pp. 7-20, 2009.

[11] M. Martins, O. A. V. Marques, and I. Sazima, "Ecological and phylogenetic correlates of feeding habits in neotropical pitvipers of the genus Bothrops," in Biology of the Vipers, G. W. Schuett, M. Höggren, M. E. Douglas, and H. W. Greene, Eds., Eagle Mountain Publishing, Eagle Mountain, Utah, Utah, 2002.

[12] M. T. Rodrigues, "Herpetofauna da caatinga," in Ecologia e conservação da caatinga, I. R. Leal, M. Tabarelli, and J. M. C. Silva, Eds., Editora Universitária da UFPE Recife, Recife, Brazil, 2003.
[13] M. Martins, M. S. Araujo, R. J. Sawaya, and R. Nunes, "Diversity and evolution of macrohabitat use, body size and morphology in a monophyletic group of Neotropical pitvipers (Bothrops)," Journal of Zoology, vol. 254, no. 4, pp. 529-538, 2001.

[14] W. Wüster, M. G. Salomão, J. A. Quijada-Mascareñas, and R. S. Thorpe, "Origin and evolution of the South American pitviper fauna: evidence from mitochondrial DNA sequence analysis," in Biology of the Vipers, G. W. Schuett, M. Höggren, M. E. Douglas, and H. W. Greene, Eds., Eagle Mountain Publishing, Eagle Mountain, Calif, USA, 2002.

[15] R. M. Lira-da-Silva, L. L. Casais-e-Silva, I. B. Queiroz, and T. B. Nunes, "Contribuição à biologia de serpentes da Bahia, Brasil. I- Vivíparas," Revista Brasileira de Zoologia, vol. 11, no. 2, pp. 187-193, 1994.

[16] W. P. Maddison and D. R. Maddison, "Mesquite: a modular system for evolutionary analysis," Version 2.75, 2011, http:// mesquiteproject.org/.

[17] P. A. Carrasco, C. I. Mattoni, G. C. Leynaud, and G. J. Scrocchi, "Morphology, phylogeny and taxonomy of South American bothropoid pitvipers (Serpentes, Viperidae)," Zoologica Scripta, vol. 41, no. 2, pp. 109-124, 2012.

[18] R. D. Aldridge, "Oviductal anatomy and seasonal sperm storage in the southeastern crowned snake (Tantilla coronata)," Copeia, vol. 1992, pp. 1103-1106, 1992.

[19] D. S. Siegel, A. Miralles, R. E. Chabarria, and R. D. Aldridge, "Female reproductive anatomy: cloaca, oviduct, and sperm storage," in Reproductive Biology and Phylogeny of Snakes, R. D. Aldridge and D. M. Sever, Eds., Science Publishers, Enfield, Conn, USA, 2011.

[20] T. Mathies, "Reproductive cycles of tropical snakes," in Reproductive Biology and Phylogeny of Snakes, R. D. Aldridge and and D. M. Sever, Eds., Science Publishers, Enfield, NH, USA, 2011.

[21] A. Cree, L. J. Guillette Jr., M. A. Brown, G. K. Chambers, J. F. Cockrem, and J. D. Newton, "Slow estradiol-induced vitellogenesis in the tuatara, Sphenodon punctatus," Physiological Zoology, vol. 64, pp. 1234-1251, 1991.

[22] C. J. Reading, "The influence of body condition and prey availability on female breeding success in the smooth snake (Coronella austriaca Laurenti)," Journal of Zoology, vol. 264, no. 1, pp. 61-67, 2004.

[23] W. Fox, "Seminal receptacles of snakes," The Anatomical Record, vol. 124, no. 3, pp. 519-539, 1956.

[24] D. M. Sever and T. J. Ryan, "Ultrastructure of the reproductive system of the black swamp snake (Seminatrix pygaea). I. Evidence for oviducal sperm storage," Journal of Morphology, vol. 241, pp. 1-18, 1999.

[25] W. Fox and H. C. Dessauer, "The single right oviduct and other urogenital structures of female Typhlops and Leptotyphlops," Copeia, vol. 1962, no. 3, pp. 590-597, 1962.

[26] A. P. Halpert, W. R. Garstka, and D. Crews, "Sperm transport and storage and its relation to the annual sexual cycle of the female red-sided garter snake, Thamnophis sirtalis parietalis," Journal of Morphology, vol. 174, no. 2, pp. 149-159, 1982.

[27] M. J. Perkins and B. D. Palmer, "Histology and functional morphology of the oviduct of an oviparous snake, Diadophis punctatus," Journal of Morphology, vol. 227, no. 1, pp. 67-79, 1996.

[28] W. Booth and G. W. Schuett, "Molecular genetic evidence for alternative reproductive strategies in North American pitvipers (Serpentes: Viperidae): long-term sperm storage and facultative parthenogenesis," Biological Journal of the Linnean Society, vol. 104, no. 4, pp. 934-942, 2011. 
[29] K. M. P. Silva, Análise do comportamento reprodutivo de Bothrops spp. em cativeiro, Universidade de Franca, São Paulo, Brazil, 2009.

[30] R. W. Krohmer, "Variation in seasonal ultrastructure of sexual granules in the renal sexual segment of the Northern Water Snake, Nerodia sipedon sipedon," Journal of Morphology, vol. 261, no. 1, pp. 70-80, 2004.

[31] C. A. Rojas, V. A. Barros, and S. M. Almeida-Santos, "The reproductive cycle of the male sleep snake Sibynomorphus mikanii (Schlegel, 1837) from southeastern brazil," Journal of Morphology, vol. 274, no. 2, pp. 215-228, 2013.

[32] X. Ji, C. X. Lin, L. H. Lin, Q. B. Qiu, and Y. Du, "Evolution of viviparity in warm-climate lizards: an experimental test of the maternal manipulation hypothesis," Journal of Evolutionary Biology, vol. 20, no. 3, pp. 1037-1045, 2007.

[33] R. D. Aldridge and D. Duvall, "Evolution of the mating season in the pitvipers of North America," Herpetological Monographs, no. 16, pp. 1-25, 2002.

[34] P. H. Valdujo, C. Nogueira, and M. Martins, "Ecology of Bothrops neuwiedi pauloensis (Serpentes: Viperidae: Crotalinae) in the Brazilian cerrado," Journal of Herpetology, vol. 36, no. 2, pp. 169-176, 2002.

[35] R. B. King, "Determinants of offspring number and size in the brown snake, Storeria dekayi," Journal of Herpetology, vol. 27, no. 2, pp. 175-185, 1993.

[36] R. Shine, "Reproductive strategies in snakes," Proceedings of the Royal Society B: Biological Sciences, vol. 270, no. 1519, pp. 9951004, 2003.

[37] M. A. Akbarsha, V. Tamilarasan, B. Kadalmani, and P. Daisy, "Ultrastructural evidence for secretion from the epithelium of ampulla ductus deferentis of the fan-throated lizard Sitana ponticeriana Cuvier," Journal of Morphology, vol. 266, no. 1, pp. 94-111, 2005.

[38] S. E. Trauth and D. M. Sever, "Male urogenital ducts and cloacal anatomy," in Reproductive Biology and Phylogeny of Snakes, R. D. Aldridge and D. M. Sever, Eds., Science Publishers, Enfield, Conn, USA, 2011.

[39] H. Saint Girons, "Reproductive cycles of male snakes and their relationships with climate and female reproductive cycles," Herpetologica, vol. 38, no. 1, pp. 5-16, 1982.

[40] M. Olsson, T. Madsen, and R. Shine, "Is sperm really so cheap? Costs of reproduction in male adders, Vipera berus," Proceedings of the Royal Society B: Biological Sciences, vol. 264, no. 1380, pp. 455-459, 1997.

[41] C. Arzabe, "Reproductive activity patterns of anurans in two different altitudinal sites within the Brazilian Caatinga," Revista Brasileira de Zoologia, vol. 16, no. 3, pp. 851-864, 1999.

[42] J. G. E. Lewis, The Biology of Centipedes, Cambridge University Press, Cambridge, UK, 1st edition, 1981.

[43] W. S. Parker and M. V. Plummer, "Population ecology," in Snakes: Ecology and Evolutionary Biology, R. A. Seigel, J. T. Collins, and S. S. Novak, Eds., MacMillan, New York, NY, USA, 1987.

[44] R. Shine, "Sexual size dimorphism in snakes revisited," Copeia, no. 2, pp. 326-346, 1994.

[45] X. Bonnet, G. Naulleau, R. Shine, and O. Lourdais, "Reproductive versus ecological advantages to larger body size in female snakes, Vipera aspis," Oikos, vol. 89, no. 3, pp. 509-518, 2000.

[46] R. Shine, "Sexual size dimorphism and male combat in snakes," Oecologia, vol. 33, no. 3, pp. 269-277, 1978.

[47] M. E. Oliveira and M. Martins, "When and where to find a pitviper: activity patterns and habitat use of the lancehead,
Bothrops atrox, in Central Amazonia, Brazil," Herpetological Natural History, vol. 8, pp. 101-110, 2001. 

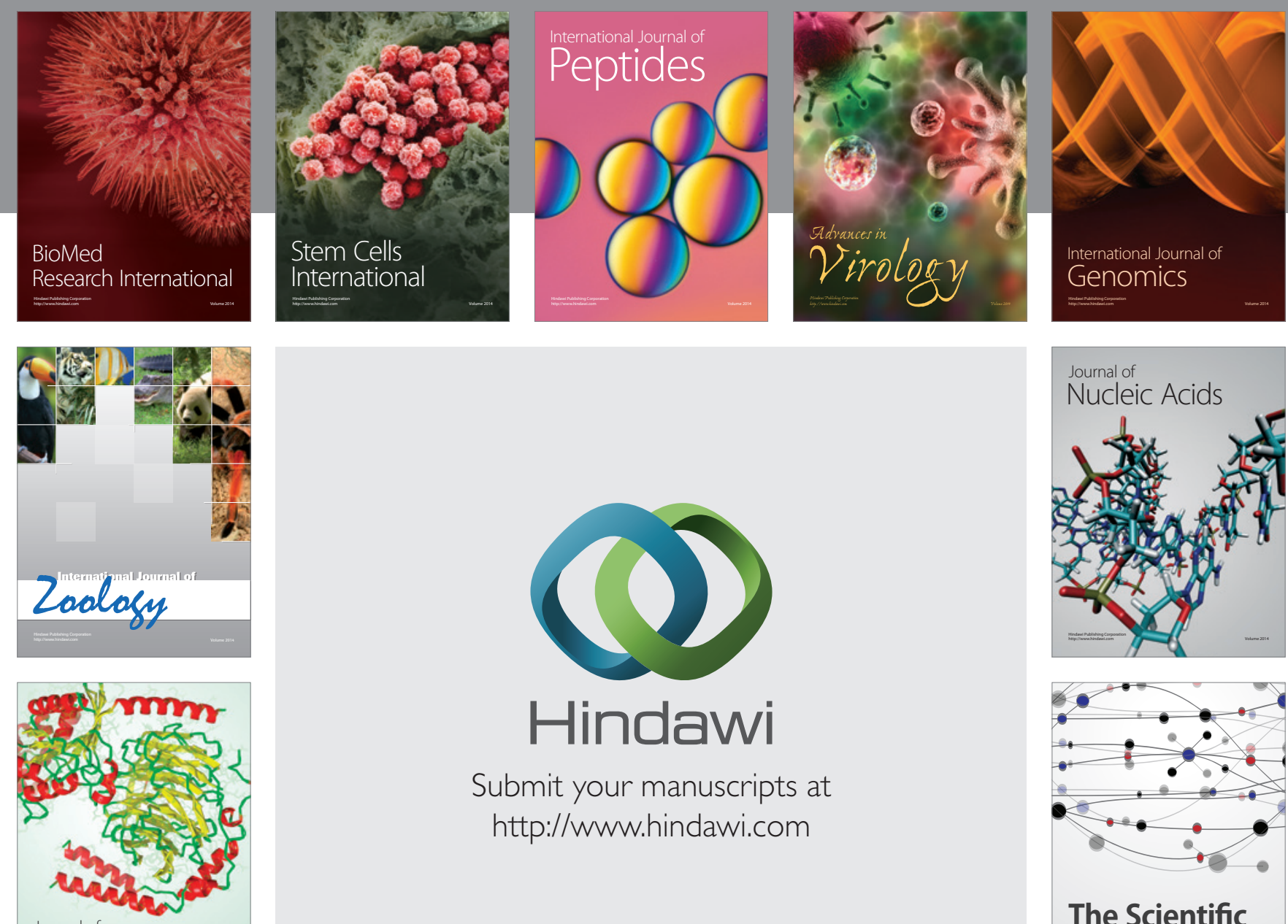

Submit your manuscripts at

http://www.hindawi.com

Journal of
Signal Transduction
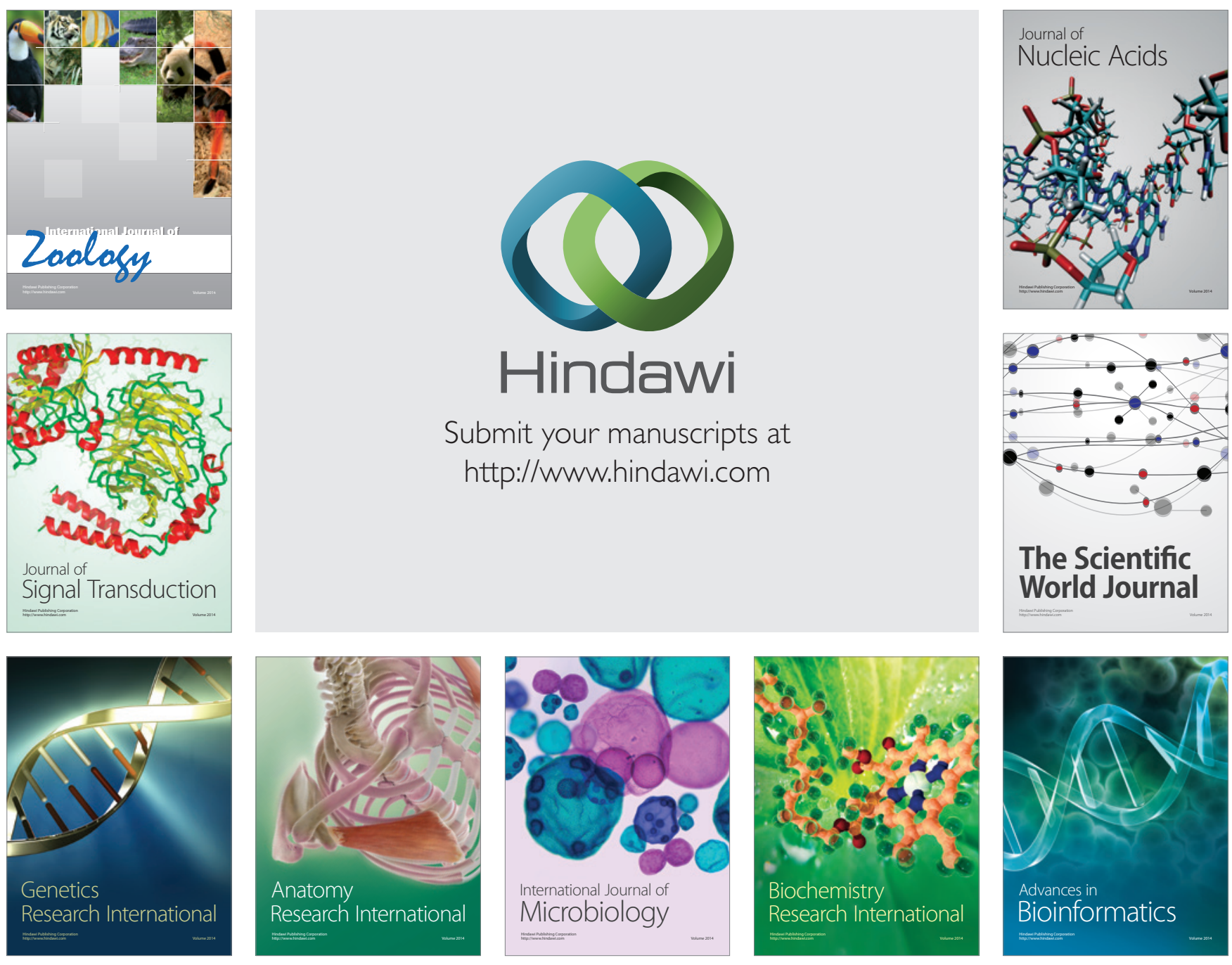

The Scientific World Journal
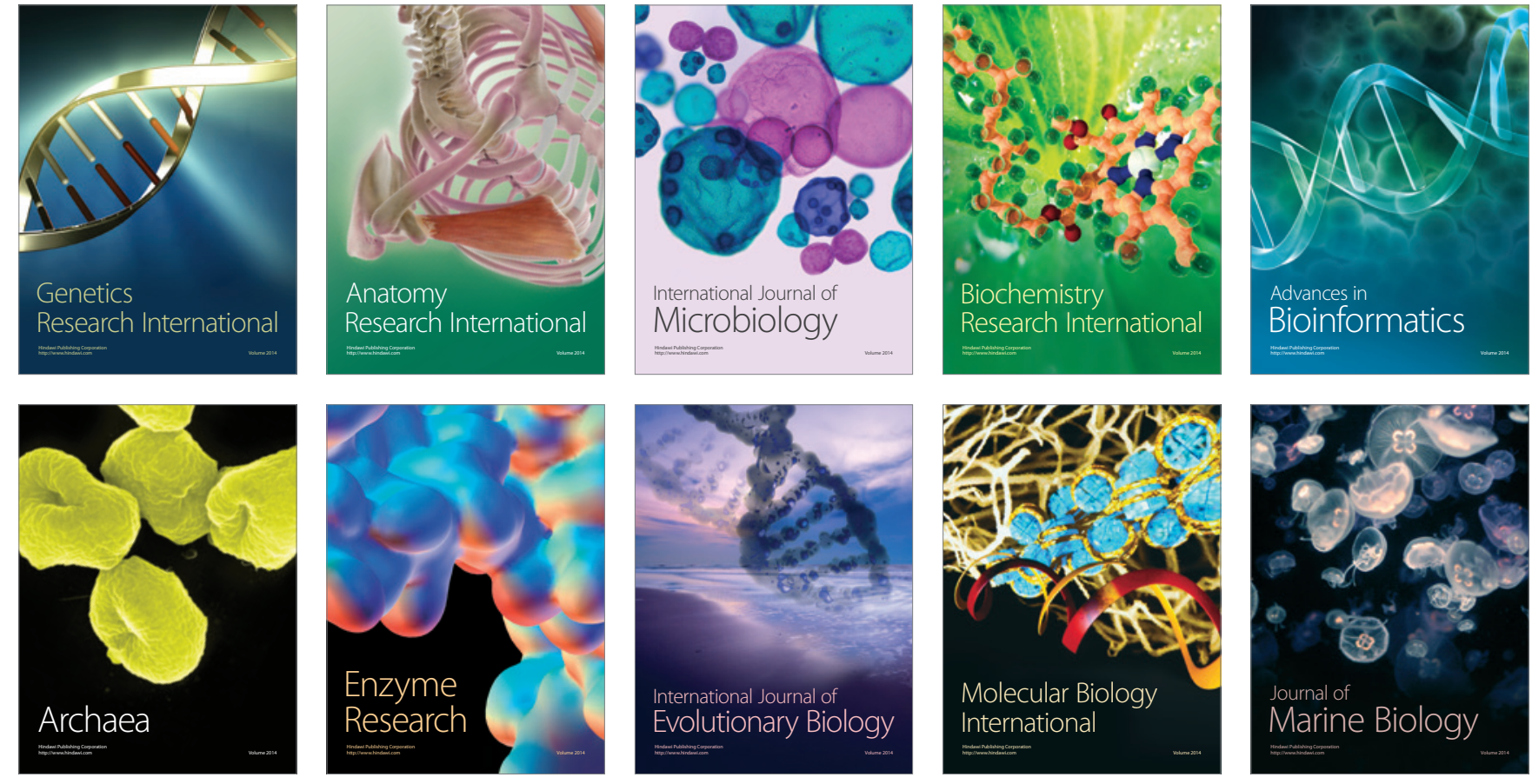